Article

\title{
Evaluation of NESMv3 and CMIP5 Models' Performance on Simulation of Asian-Australian Monsoon
}

\author{
Juan $\mathrm{Li}^{1, *(1)}$, Young-Min Yang ${ }^{2}$ (i) and Bin Wang ${ }^{1,2}$ \\ 1 Earth System Modeling Center, Nanjing University of Information Science and Technology, Nanjing 210044, \\ China; wangbin@hawaii.edu \\ 2 Department of Atmospheric Sciences and IPRC, University of Hawaii at Manoa, Honolulu, HI 96822, USA; \\ ymyang@hawaii.edu \\ * Correspondence: juanl@hawaii.edu
}

Received: 7 June 2018; Accepted: 14 August 2018; Published: 21 August 2018

\begin{abstract}
The Asian-Australian monsoon (AAM) has far-reaching impacts on global and local climate. Accurate simulations of AAM precipitation and its variabilities are of scientific and social importance, yet remain a great challenge in climate modeling. The present study assesses the performance of the newly developed Nanjing University of Information Science and Technology Earth System Model version 3 (NESMv3), together with that of 20 Coupled Model Intercomparison Project phase 5 (CMIP5) models, in the simulation of AAM climatology, its major modes of variability, and their relationships with El Nino-Southern Oscillation (ENSO). It is concluded that NESMv3 (1) reproduces, well, the observed features of AAM annual mean precipitation; (2) captures the solstice mode (the first annual cycle mode) of AAM realistically, but has difficulty in simulating the equinox mode (the second annual cycle mode) of AAM; (3) underestimates the monsoon precipitation intensity over the East Asian subtropical frontal zone, but overestimates that over the tropical western North Pacific; (4) faithfully reproduces the first season-reliant empirical orthogonal function (SEOF) mode of AAM precipitation and the associated circulation anomalies, as well as its relationship with ENSO turnabout, although the correlation is underestimated. Precipitation anomaly patterns of the second SEOF mode and its relationship with El Nino are poorly simulated by NESMv3 and most of the CMIP5 models as well, indicating that the monsoon variability prior to the ENSO onset is difficult to reproduce. In general, NESMv3's performance in simulating AAM precipitation ranks among the top or above-average compared with the 20 CMIP5 models. Better simulation of East Asian summer monsoon and western Pacific subtropical high remains a major target for future improvement, in order to provide a reliable tool to understand and predict AAM precipitation.
\end{abstract}

Keywords: NESMv3; Asia-Australian monsoon; ENSO

\section{Introduction}

The Asian-Australian monsoon (AAM) system, which consists of the Asian monsoon and its southern hemisphere counterpart, the Indonesian-Australian monsoon, has far-reaching impacts on global climate, economic development and human life [1-3]. Understanding the variability of AAM and improving the predictions on AAM have the potential to provide considerable social-economic returns.

The strong year-to-year precipitation variations in the AAM domain $\left(30^{\circ} \mathrm{S}-40^{\circ} \mathrm{N}, 60^{\circ} \mathrm{E}-160^{\circ} \mathrm{E}\right)$ exhibit significant regional differences, and depend heavily on the seasonal march and evolution of El Nino-Southern Oscillation (ENSO) [4-7]. In addition, monsoon-warm pool interaction is another vital factor that regulates AAM variability [7-9]. In the absence of monsoon-warm ocean interactions, 
atmospheric general circulation models have difficulty in capturing the variability of AAM $[8,10]$. Thus, to improve the capability of dynamical models in prediction of AAM, it is necessary to use and develop coupled ocean-atmosphere models that consider the local monsoon-warm ocean interactions. Whether AAM precipitation can be accurately simulated and predicted has become the most rigorous and key test for coupled climate models [11-13].

Recently, Nanjing University of Information Science and Technology (NUIST) Earth System Model version 3 (NESMv3) has been developed. NESMv3 has participated in the ongoing Coupled Model Intercomparison Project (CMIP) (phase 6) experiments (CMIP6) for Intergovernmental Panel on Climate Change Sixth Assessment Report. A previous study has shown that the CMIP phase 5 (CMIP5) [14] models have some problems in simulating AAM in terms of climatology and year-to-year variability [15]. How this newly developed model performs in simulating AAM is an imperative issue to be investigated. This study aims to evaluate the performance of NESMv3 in simulating AAM precipitation, including climatological mean state, annual cycle, monsoon intensity, and domain, and major modes of AAM. To facilitate multi-model intercomparison, 20 coupled models that participated in CMIP5 are also assessed. The metrics used for evaluation would provide a basis for appraising the reliability of global models' projection about AAM precipitation.

\section{Data, Model, and Method}

\subsection{Observed Data}

Monthly precipitation data used in the present study are obtained from an arithmetic mean of two datasets: the Global Precipitation Climatology Project (GPCP, v2.3) dataset [16], and the Climate Prediction Center Merged Analysis of Precipitation (CMAP) dataset [17]. It is noted that the difference between CMAP and GPCP is not significant in terms of climatology [18]. Adopting their mean may improve the reliability of observed data. For monthly mean sea surface temperature (SST), we use the National Oceanic and Atmospheric Administration Extended Reconstructed SST version 4 [19]. All datasets cover the period of 1979-2005.

\subsection{Models}

NESMv3 [20] is evaluated in detail. The atmospheric component of this coupled model is the European Centre Hamburg Model (ECHAMv6.3) [21] with a horizontal resolution of $1.875^{\circ}$ by $1.875^{\circ}$ in longitude and latitude, and 47 levels of vertical resolution. The Nucleus for European Modeling of the Ocean (NEMO, v3.4) [22], with a $1^{\circ} \times 1^{\circ}$ horizontal resolution and 46 vertical levels, is employed as the oceanic component model. The sea-ice component model is version 4.1 of the Los Alamos sea-ice model (CICE) [23]. The coupler is Ocean-Atmosphere-Sea-Ice-Soil Model Coupling Toolkit (OASIS3-MCT) [24]. Same as the experimental design of CMIP5 historical run [14], the NESMv3 model is imposed with changing conditions, consistent with observations from 1850 to 2005, which include atmospheric composition (e.g., CO2) due to both anthropogenic and volcanic influences, solar forcing, emissions, or concentrations of short-lived species, natural and anthropogenic aerosols or their precursors, and land use.

To facilitate multi-model intercomparison, historical simulations of 20 coupled global circulation models (CGCMs) from CMIP5 are used for evaluation for the modern period. Table 1 lists the basic information of 20 CMIP5 models selected in the present study. The CMIP5 simulations are from 1850 to 2005, but the period of 1979-2005 is analyzed for CMIP5 simulations, herein, because the observed data have better quality during this period. The multi-model ensemble (MME) mean of 20 CMIP5 CGCMs is constructed with equal weights. For fair comparison, all data are interpolated to the resolution of $2.5^{\circ} \times 2.5^{\circ}$ by using the bilinear method. 
Table 1. Description of CMIP5 models used in the present study.

\begin{tabular}{|c|c|c|}
\hline Model Designation & Institution & $\begin{array}{l}\text { Resolution (Longitude } \\
\quad \times \text { Latitude) }\end{array}$ \\
\hline ACCESS1-0 & $\begin{array}{l}\text { Commonwealth Scientific and Industrial Research Organisation and Bureau of } \\
\text { Meteorology (CSIRO-BOM), Australia }\end{array}$ & $1.875^{\circ} \times 1.25^{\circ}$ \\
\hline BCC-CSM1.1-m & Beijing Climate Center, China Meteorological Administration (BCC), China & $1.125^{\circ} \times 1.125^{\circ}$ \\
\hline CanESM2 & Canadian Centre for Climate Modelling and Analysis (CCCma), Canada & $2.8125^{\circ} \times 2.8125^{\circ}$ \\
\hline CNRM-CM5 & $\begin{array}{l}\text { Centre National de Recherches Meteorologiques/Centre Europeen de Recherche et } \\
\text { Formation Avancees en Calcul Scientifique (CNRM-CERFACS), France }\end{array}$ & $1.40625^{\circ} \times 1.40625^{\circ}$ \\
\hline CSIRO-Mk3-6-0 & $\begin{array}{l}\text { Commonwealth Scientific and Industrial Research Organisation and the } \\
\text { Queensland Climate Change Centre of Excellence (CSIRO-QCCCE), Australia }\end{array}$ & $1.875^{\circ} \times 1.875^{\circ}$ \\
\hline FGOALS-g2 & $\begin{array}{l}\text { LASG, Institute of Atmospheric Physics, Chinease Academy of Sciences; and CESS, } \\
\text { Tsinghua University (LASG-CESS), China }\end{array}$ & $2.8125^{\circ} \times 2.8125^{\circ}$ \\
\hline INM-CM4 & Institute for Numerical Mathematics (INM), Russia & $2^{\circ} \times 1.5^{\circ}$ \\
\hline $\begin{array}{l}\text { IPSL-CM5A-LR } \\
\text { IPSL-CM5A-MR } \\
\text { IPSL-CM5B-LR }\end{array}$ & Institute Pierre-Simon Laplace (IPSL), France & $\begin{array}{l}3.75^{\circ} \times 1.875^{\circ} \\
2.5^{\circ} \times 1.258^{\circ} \\
3.75^{\circ} \times 1.875^{\circ}\end{array}$ \\
\hline $\begin{array}{l}\text { MIROC5 } \\
\text { MIROC-ESM-CHEM }\end{array}$ & $\begin{array}{l}\text { Atmosphere and Ocean Research Institute (University of Tokyo), National Institute } \\
\text { for Environmental Studies, and Japan Agency for Marine-Earth Science and } \\
\text { Technology (MIROC), Japan }\end{array}$ & $\begin{aligned} 1.40625^{\circ} & \times 1.40625^{\circ} \\
2.8125^{\circ} & \times 2.8125^{\circ}\end{aligned}$ \\
\hline $\begin{array}{l}\text { MPI-ESM-LR } \\
\text { MPI-ESM-P }\end{array}$ & Max Planck Institute for Meteorology (MPI-M), Germany & $\begin{array}{l}1.875^{\circ} \times 1.875^{\circ} \\
1.875^{\circ} \times 1.875^{\circ}\end{array}$ \\
\hline MRI-CGCM3 & Meteorological Research Institute (MRI), Japan & $1.125^{\circ} \times 2.25^{\circ}$ \\
\hline
\end{tabular}

\subsection{Objective Measures}

To quantify the performance of models, three objective measures are applied to the metrics fields. One is the pattern correlation coefficient (PCC), which is used to gauge the degree of similarity of patterns of observed and simulated variables $[25,26]$. The second one is domain-averaged normalized root mean square error (NRMSE) [18], which is adopted to measure the error magnitude in simulation. NRMSE is the root mean square error normalized by the observed standard deviation that is calculated with reference to the whole domain. The third measure is the threat score (TS), which is defined by the number of hit grids divided by the sum of hit, missed, and false-alarm grids. It is used to appraise the performance on the monsoon domain [27].

The formulas of these measures are shown as follows:

$$
\begin{gathered}
\operatorname{PCC}(X, Y)=\frac{\operatorname{Cov}(X, Y)}{\sqrt{\operatorname{Var}[X] \operatorname{Var}[Y]}} \\
\text { NRMSE }=\frac{\sqrt{\frac{1}{n} \sum_{i=1}^{n}\left(x_{\mathrm{i}}-y_{\mathrm{i}}\right)^{2}}}{\operatorname{Var}[X]} \\
\text { TS }=\frac{\text { num(hit) }}{\text { num(hit) }+ \text { num(miss })+ \text { num(false) }}
\end{gathered}
$$

$X\left(x_{i}, i=1, \ldots, n\right), Y\left(y_{i}, i=1, \ldots, n\right)$ are two series. They are, respectively, the observed and simulated values at corresponding grids (the total number of grids is $n$ ) on the same map. "Cov" is the covariance. "Var" is the standard deviation. "num" is the number of grids. 


\section{Results}

\subsection{Monsoon Climatology}

Over the global domain, NESMv3 can well capture the climatological annul mean SST and precipitation with NRMSE of 0.09 and 0.49 , respectively. However, the model suffers a cold SST bias in the North Atlantic and western North Pacific, and a warm bias in the equatorial eastern Pacific [28]. The SST bias over the tropic Pacific may weaken the Walker circulation and affect AAM. NESMv3 has a delicate double Intertropical Convergence Zone bias, which is associated with insufficient precipitation over the equatorial Pacific [28].

Concerning the AAM domain, Figure 1 shows the observed and NESMv3-simulated monsoon climatology for 1979-2005, and the model bias resulted from NESMv3 simulation minus the observation. A comprehensive evaluation of the monsoon climatology should take into account the following four metrics [15]: the annual mean precipitation, the annual cycle (seasonal evolution), the monsoon precipitation intensity and the monsoon domain. Firstly, we evaluate the model's performance on the annual mean precipitation. It can be seen that NESMv3 reproduces well $($ PCC = 0.90 , NRMSE $=0.45$ ) the observed features of annual mean precipitation, including the major oceanic tropical convergence zones over the Indian Ocean and western Pacific, and the subtropical rain belts over eastern China and Japan. A difference map between the observation and NESMv3 simulation indicates that NESMv3 tends to underestimate precipitation over the equatorial eastern Indian Ocean and the Bay of Bengal, but overestimate precipitation over the equatorial western Indian Ocean. Moreover, it overestimates precipitation over the Maritime Continent, Philippines, and Tibetan Plateau, but underestimates precipitation over the ocean south and east of Japan (the Kuroshio region).

A monsoon is traditionally defined as a seasonal reversing wind accompanied by corresponding changes in precipitation, therefore, the annual cycle (seasonal evolution) is an important property of monsoon. To assess the model's capability to reproduce the seasonal evolution, the first two annual cycle modes are examined. The first annual cycle mode reflects the atmospheric circulation response to the anti-symmetric solar forcing in solstice seasons, therefore, it is called the monsoon solstice mode [29]. It can be represented well by the difference between June-July-August-September and December-January-February-March mean precipitation [29]. NESMv3 realistically reproduces the first annual cycle mode with a PCC of 0.89 and NRMSE of 0.60 . However, this model tends to overestimate the precipitation range over the south of India, the Indo-China Peninsula, the Philippines, the tropical western North Pacific, and the Tibetan Plateau, but underestimate the rainfall range over Australia, the tropical southern Indian Ocean, the Maritime Continent and eastern China, the Korean Peninsula, and Japan.

The second annual cycle mode reflects a spring-fall asymmetric response and consequently, it is dubbed the equinox asymmetric mode. This mode can be represented by the April-May mean precipitation minus the October-November mean precipitation [29]. NESMv3 has difficulty in simulating the equinox mode over the AAM region $(\mathrm{PCC}=0.56)$. The major bias in simulation can be found over the South China Sea, Indian Ocean, and western Maritime Continent. In the AAM region, the wind departure associated with the seasonal transition of subtropical zonal land-ocean thermal contrast might be the primary reason for the spring-fall asymmetry [29], implying that the model has deficiencies in capturing this subtropical process. 
(a) Observation

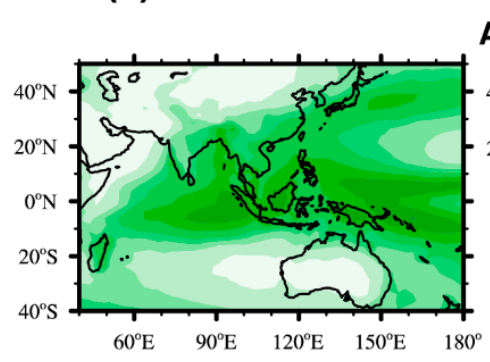

(b) NESM-V3 Annual mean precipitation ( $\mathrm{mm} / \mathrm{day})$ (c) Bias

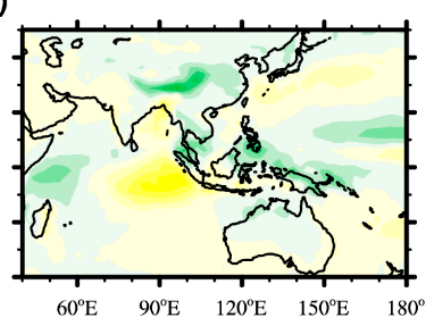

The first annual cycle ( $\mathrm{mm} /$ day)
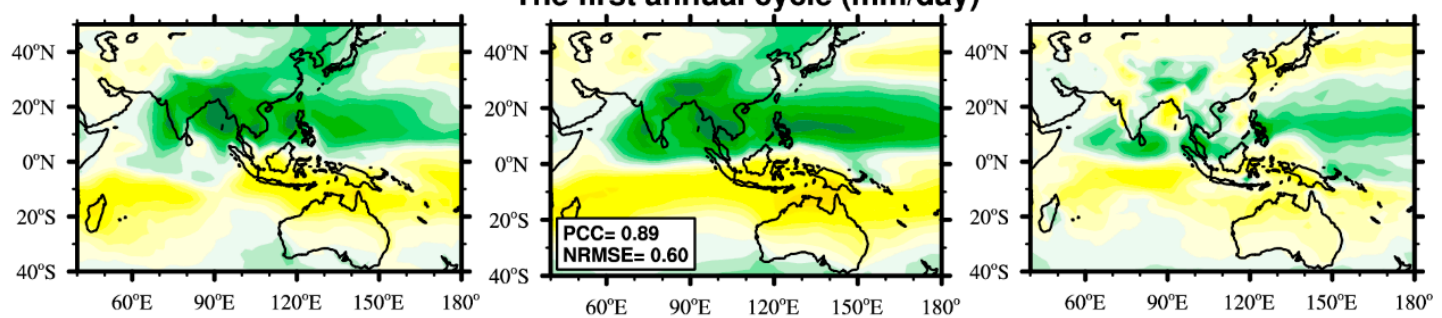

The second annual cycle ( $\mathrm{mm} / \mathrm{day})$
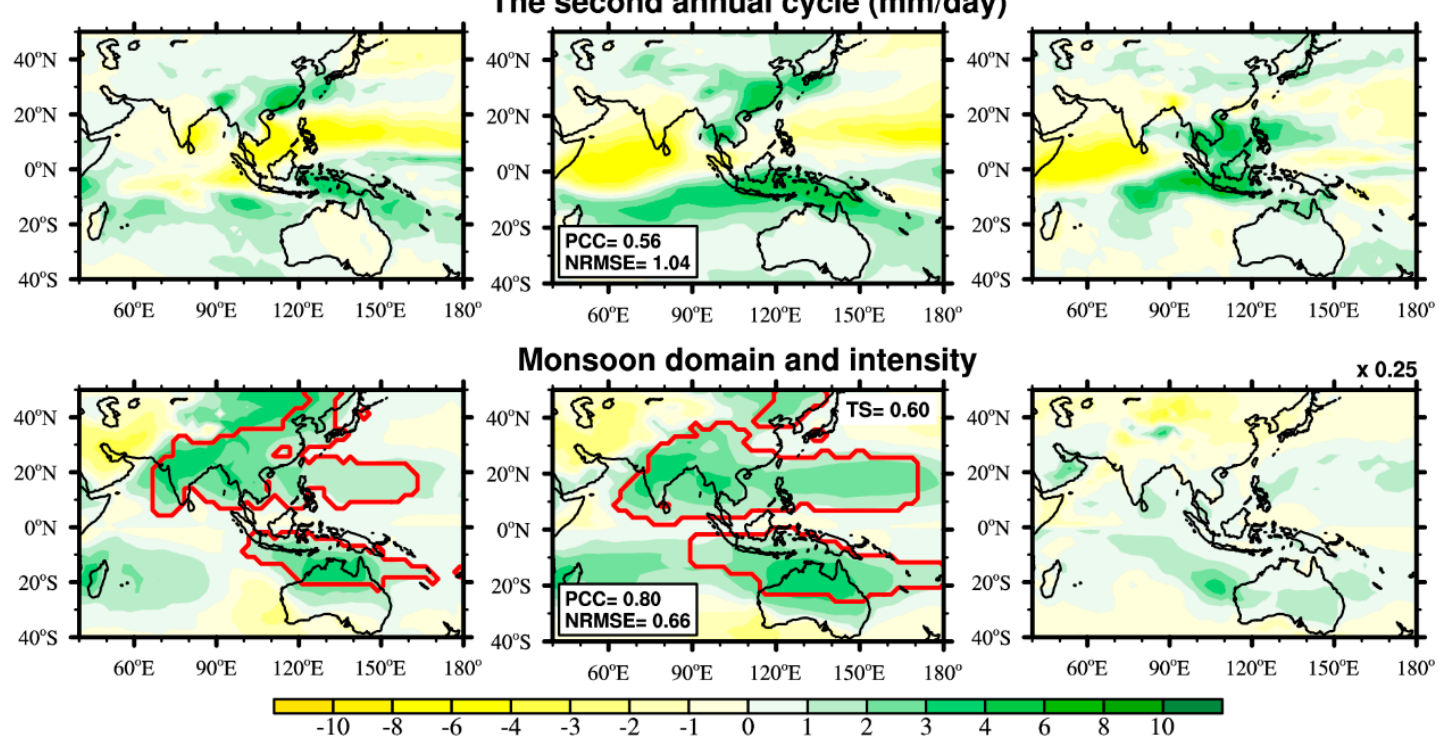

Figure 1. Comparison of (a) observed and (b) NESMv3-simulated monsoon climatology for 1979-2005, and (c) bias between (b) and (a) in terms of annual mean precipitation rate ( $\mathrm{mm} /$ day), the first annual cycle mode (solstice mode, June-July-August-September minus December-January-February-March [29]), the second annual cycle mode (equinox asymmetric mode, April-May minus October-November [29]), and monsoon domain and precipitation intensity [15,29] (nondimensional and need to multiply 0.25 for the original value). The monsoon precipitation domain (outlined by red contours) is defined as the regions in which the summer-minus-winter precipitation exceeds $2.5 \mathrm{~mm} /$ day, and the summer precipitation exceeds $55 \%$ of the annual total [27], where summer denotes May-June-July-August-September (November-December-January-February-March) for the Northern Hemisphere (Southern Hemisphere). The numbers in the left lower corners indicate pattern correlation coefficient (PCC) and normalized root mean square error (NRMSE) between the observed and simulated patterns over $40^{\circ} \mathrm{S}-50^{\circ} \mathrm{N}, 40^{\circ} \mathrm{E}-180^{\circ}$. The number in the right upper corner indicates the threat score (TS) for the monsoon precipitation domain.

The monsoon precipitation intensity is defined by the ratio of local summer (MJJAS for Northern Hemisphere, NDJFM for Southern Hemisphere) minus winter (NDJFM for Southern Hemisphere, MJJAS for Northern Hemisphere) precipitation to the annual mean precipitation, which reflects 
integrated information considering both the annual variation (local summer-minus-winter) and the relative amount of local summer rainfall with respect to the annual mean precipitation $[15,29]$. In general, the NESMv3-simulated monsoon precipitation intensity over the AAM region agrees reasonably well with the observation $(\mathrm{PCC}=0.80$, NRMSE $=0.66$ ). However, it is noteworthy that NESMv3 underestimates the monsoon precipitation intensity over the middle and lower reaches of the Yangtze River, the Korean Peninsula, and southern Japan. These regions are the subtropical East Asian summer monsoon (i.e., Meiyu-Baiu-Changma) region [30]. On the contrary, NESMv3 overestimates the monsoon precipitation intensity over the tropical western Pacific, the area where the western North Pacific summer monsoon locates. The out-phase relationship of the subtropical East Asian summer monsoon and the tropical western North Pacific summer monsoon is jointly controlled by the western North Pacific anticyclonic/cyclonic circulation anomalies, resulting in a coupled tropical-subtropical monsoon system. The underestimates (overestimates) of the subtropical East Asian summer monsoon rainfall (the tropical western North Pacific summer monsoon rainfall) may suggest that NESMv3 simulates a weaker or southward shifted western North Pacific anticyclonic/cyclonic anomaly compared to the observed one.

The monsoon domain is defined as the region where the summer-minus-winter precipitation exceeds $2.5 \mathrm{~mm} /$ day and the monsoon precipitation intensity exceeds 0.55 [27]. The monsoon rainfall domain simulated by NESMv3 is in general agreement with observations. However, the model fails to capture the monsoon domain over parts of eastern China and the East China Sea. Meanwhile, the monsoon domain over the Bay of Bengal, the South China Sea, the western North Pacific, the Maritime Continent, and Australia is exaggerated. Again, these may relate to the fact that the subtropical East Asian (tropical western North Pacific) summer monsoon rainfall is underestimated (overestimated) in NESMv3.

Figure 2 shows the performance of 20 CMIP5 models, MME, and NESMv3 in simulating the AAM precipitation climatology in a more direct way using areal-mean metrics over the region of $40^{\circ} \mathrm{S}-50^{\circ} \mathrm{N}, 40^{\circ} \mathrm{E}-180^{\circ}$. For the annual mean precipitation, NESMV3 shows a better result than all the CMIP5 models (PCC $=0.90$, NRMSE $=0.45$ ), and very close to that of the MME (Figure 2a). As to the annual cycle, NESMv3 delivers an outstanding performance for the solstice mode (Figure 2b), but it has an ordinary performance for the equinox asymmetric mode (Figure 2c) due to the abovementioned model deficiencies. For the monsoon precipitation intensity and monsoon domain, NESMv3 presents a medium capability, with a PCC of 0.80 for monsoon precipitation intensity, and a TS of 0.6 for monsoon domain.

(a) AM

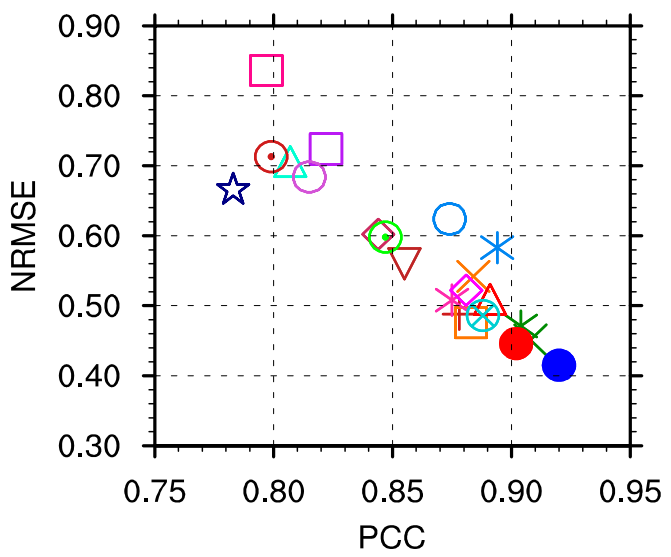

(b) AC1

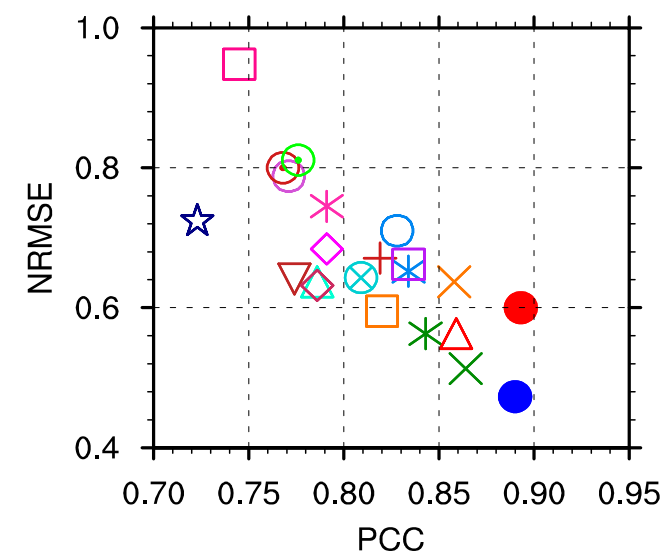

Figure 2. Cont. 
(c) AC2

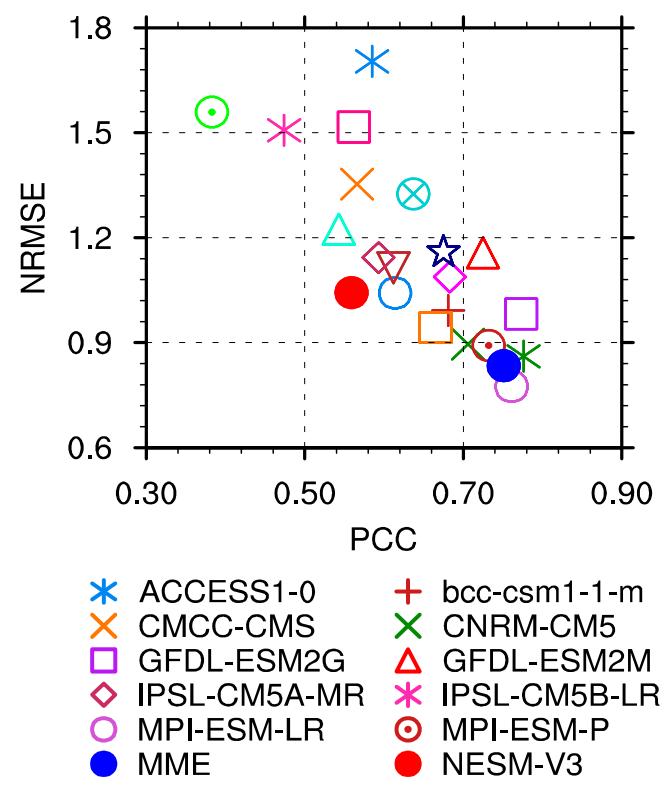

(d) MPI and monsoon domain

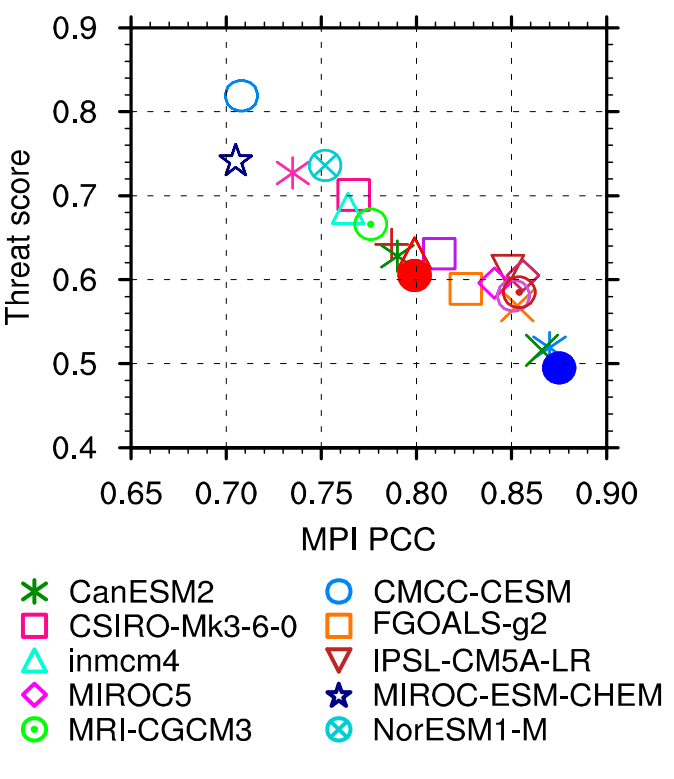

Figure 2. The models' performance on simulation of Asian-Australian monsoon (AAM) precipitation climatology (1979-2005): (a) annual mean precipitation (AM), (b) the solstice mode (AC1), (c) the equinox mode (AC2) and (d) monsoon precipitation intensity (MPI) and monsoon domain (measured by threat score) over $40^{\circ} \mathrm{S}-50^{\circ} \mathrm{N}, 40^{\circ} \mathrm{E}-180^{\circ}$.

\subsection{Year-To-Year Variability and Its Relationship with ENSO}

AAM has pronounced year-to-year variability, but this variability evolves with a strong annual cycle. Taking into account the unique physical features of AAM, a season-reliant empirical orthogonal function (SEOF) analysis method [31] is applied to evaluate the models' performance in simulating the leading two modes of AAM year-to-year variability with seasonal evolution [13,15].

Since these two modes are related to ENSO [6], NESMv3's performance on ENSO is firstly examined (Figure 3). The model can realistically capture ENSO phase-locking, which is characterized by a maximum peak in November-January, although the amplitude in November-January is relatively weaker. The major peak of Nino3.4 index spectrum is about 2-7 years. NESMv3 simulates the frequency of Nino3.4 index well, with major peaks at $2-5$ years. In addition, NESMv3 has a westward-shifted major variability center compared with observations. Overall, NESMv3 faithfully reproduces ENSO's main characteristics.

Figure 4 shows the spatial pattern of precipitation with seasonal sequence for the observed and simulated first SEOF mode of AAM year-to-year variation. The seasonal sequences are JJA(0), $\operatorname{SON}(0), \operatorname{DJF}(0 / 1)$, and MAM(1). Here, " 0 " denotes the year 0 and " 1 " denotes the following year (year 1). As shown in the observation (Figure 4a, left panels), in JJA(0), dry anomalies are found over the equatorial eastern Indian Ocean and Maritime Continent, while wet anomalies appear over the western Pacific and extend northwestward to the Philippine Sea, the South China Sea, and the northern Bay of Bengal. During SON(0), the suppressed convection over the equatorial eastern Indian Ocean and Maritime Continent intensifies and expands northeastward, covering the Philippine archipelago, the South China Sea, and the eastern Bay of Bengal. Enhanced rainfall is found over the western Indian Ocean. In DJF(0/1), the entire anomalies move eastward with the driest center occurring in the Philippine Sea. Southern China becomes wetter than normal. During MAM(1), the suppressed convection decays rapidly, and moves further eastward with the maximum center located at the equatorial western Pacific $\left(105^{\circ} \mathrm{E}\right)$. The wet anomalies over the western Indian Ocean are enhanced and extended to the eastern Indian Ocean. 

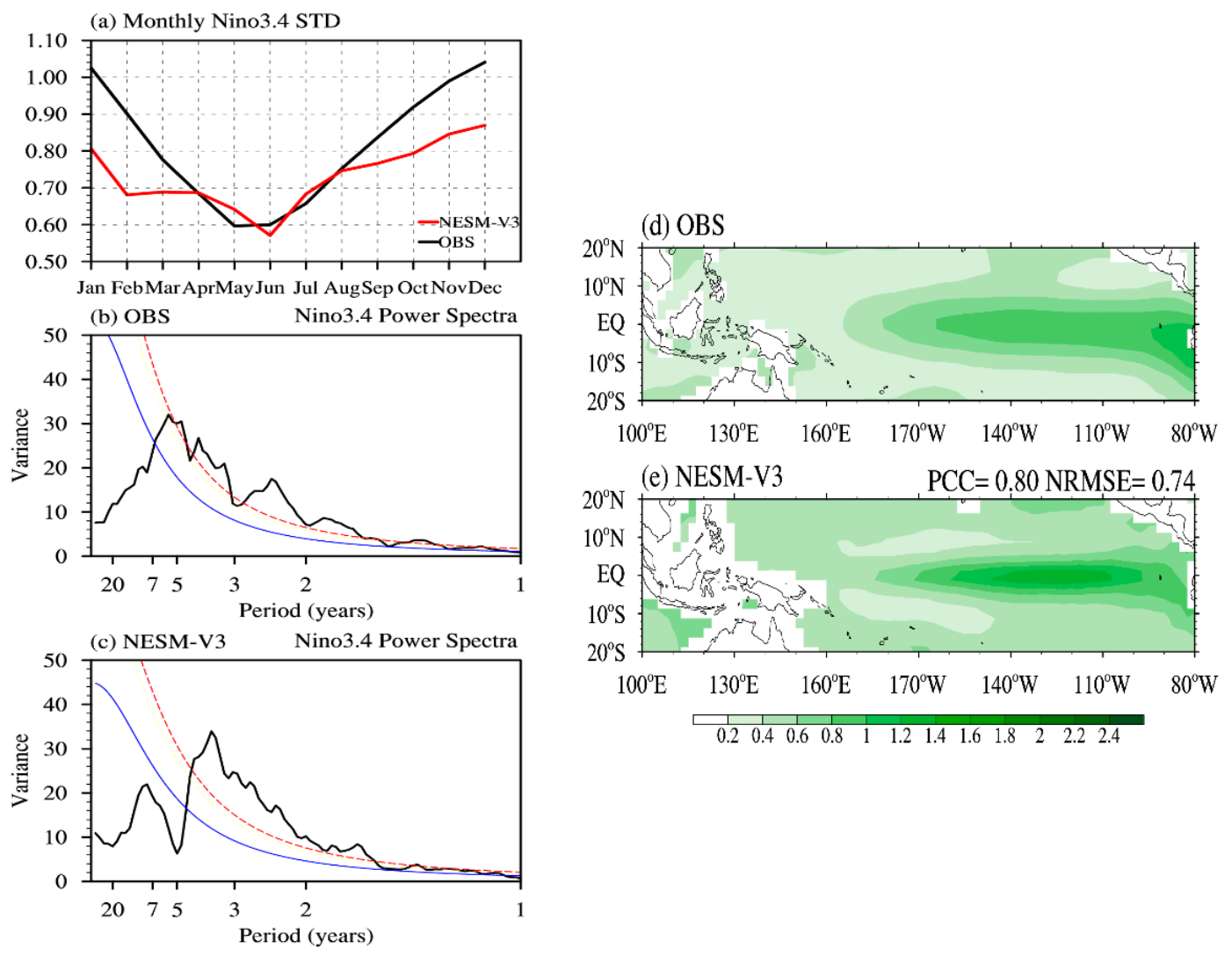

Figure 3. (a) Monthly standard deviation (STD) of Nino3.4 SST anomalies, and power spectra of Nino3.4 SST anomaly in (b) observation and (c) NESMv3. In (b,c), the blue lines indicate red noise, and the red dashed lines indicate the $95 \%$ confidence level. Interannual variance of (d) observed and (e) NESMv3 simulated monthly SST.

Figure 5 shows the seasonal evolutions of the spatial patterns of SST and $850 \mathrm{hPa}$ wind anomalies, which are correlated with the corresponding PC of the first SEOF mode in observation and simulation. For observation (Figure 5a), the warm SST anomalies over the equatorial central-eastern Pacific associated with $\mathrm{PC} 1$ appear in JJA(0), peak in $\mathrm{DJF}(0 / 1)$, and decay in $\operatorname{MAM}(1)$, suggesting that the first SEOF mode has the same evolution phase with ENSO. The remote El Nino forcing plays a major role in formation of the AAM anomalies, while the air-sea interaction is regarded as another physical factor that determines the variability of AAM [7]. During JJA(0), an anomalous anticyclone ridge extends from the Maritime Continent to the Arabian Sea, with enhanced westerlies stretching from India to the western Pacific. In SON(0), the south Indian Ocean (SIO) anticyclone is well established. It has warm SST to its west, and cold SST to its east, which can intensify the SIO anticyclone through local air-sea interaction [7]. Meanwhile, the western North Pacific (WNP) anticyclone forms over the northern Philippines. From $\operatorname{DJF}(0 / 1)$ to MAM(1), the SIO anticyclone decays, while the WNP anticyclone rapidly develops in $\operatorname{DJF}(0 / 1)$ and persists in $\operatorname{MAM}(1)$. The dipole SST pattern with warm SST to the west and cold SST to the east plays an important role in maintenance of the WNP anticyclone [7]. The SIO and WNP anticyclones dominate the AAM anomalies. The SIO anticyclone causes anomalous rainfall over the Maritime Continent, whereas the WNP anomalous anticyclone is responsible for precipitation anomalies over Southeast Asia, East Asia, and the WNP. 
(a) The first S-EOF mode of precipitation OBS (24.3\%) NESM-V3 (14.4\%)
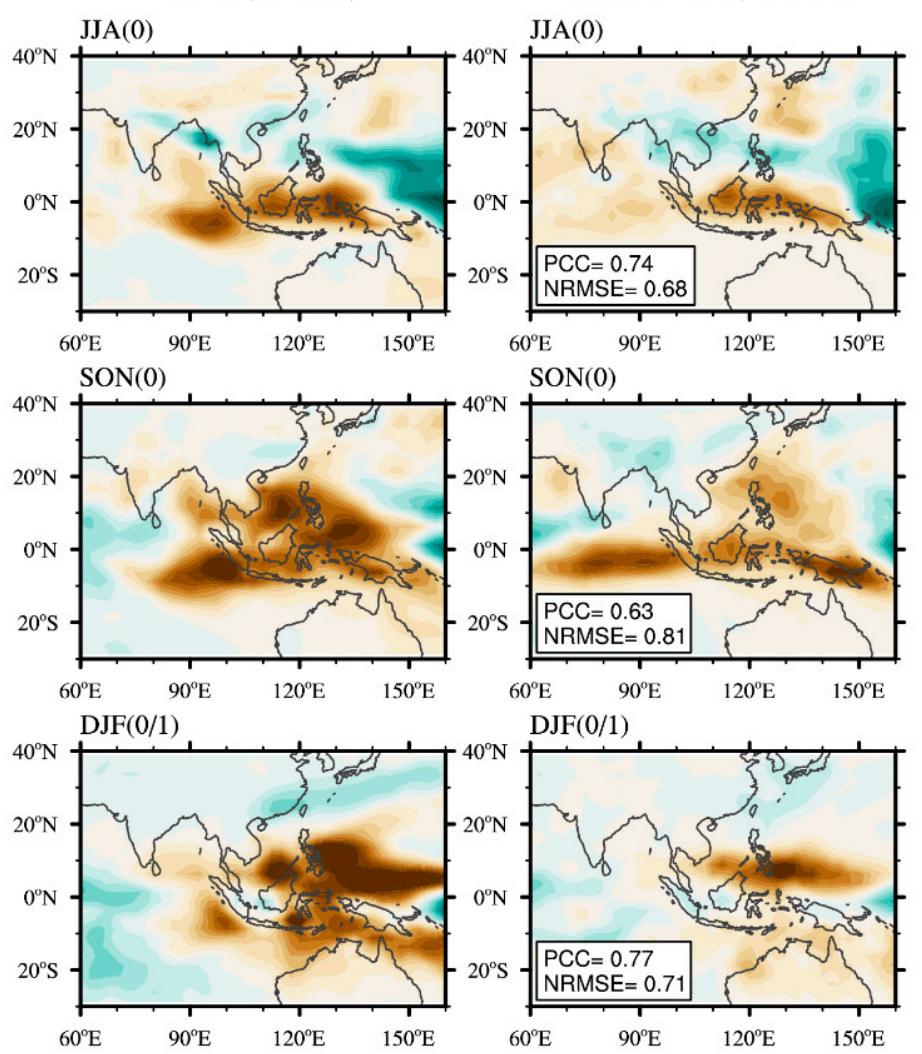

$\mathrm{DJF}(0 / 1)$
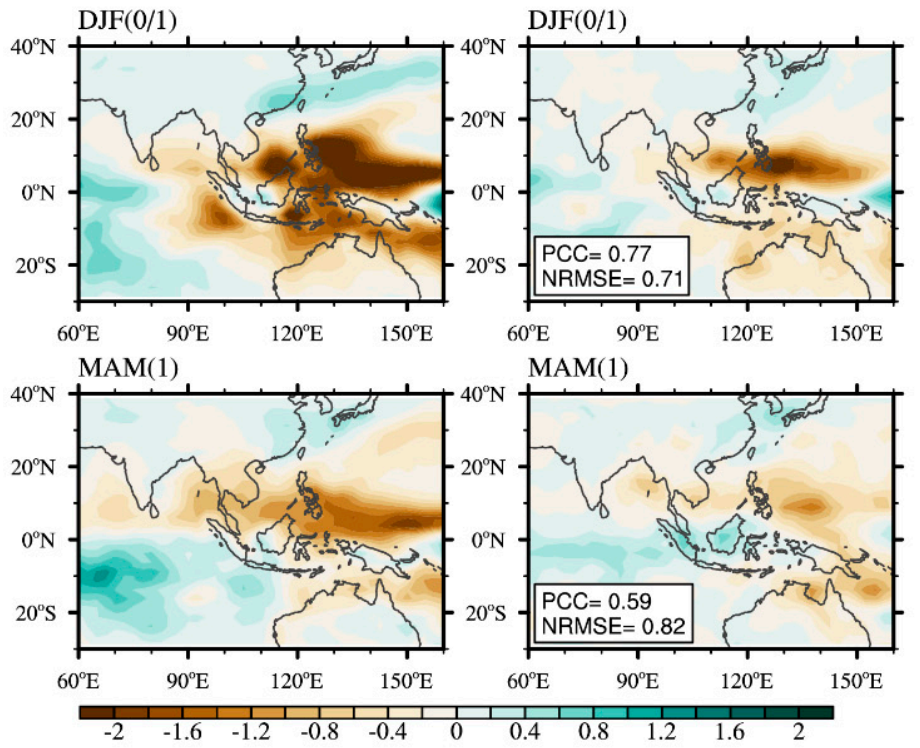

(b) Lead-lag correlation coefficients

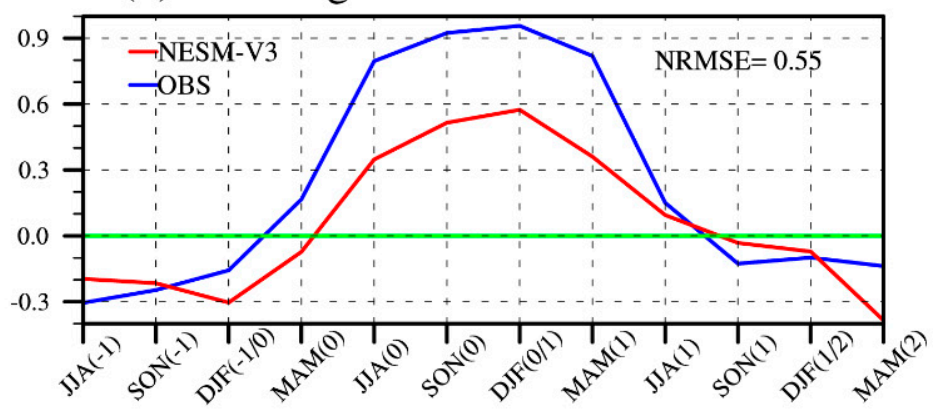

Figure 4. (a) The observed and NESMv3-simulated first season-reliant EOF (SEOF) mode of seasonal precipitation over the AAM region $\left(30^{\circ} \mathrm{S}-40^{\circ} \mathrm{N}, 60^{\circ} \mathrm{E}-160^{\circ} \mathrm{E}\right)$ during $1979-2005$. The numbers in the left bottom corner indicate PCC and NRMSE; (b) Lead-lag correlation coefficients of Nino3.4 index with reference to the first SEOF principle component. The number in the right upper corner indicates the NRMSE between observed (blue curve) and simulated (red curve) time series of lead-lag correlation coefficients. 
(a) OBS
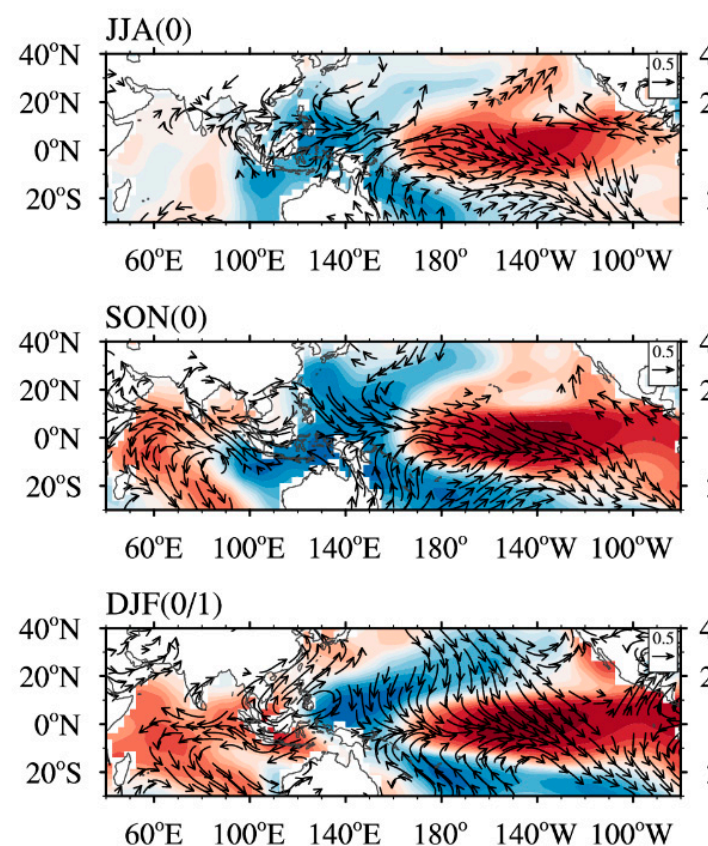

$60^{\circ} \mathrm{E} \quad 100^{\circ} \mathrm{E} \quad 140^{\circ} \mathrm{E} \quad 180^{\circ} \quad 140^{\circ} \mathrm{W} \quad 100^{\circ} \mathrm{W}$

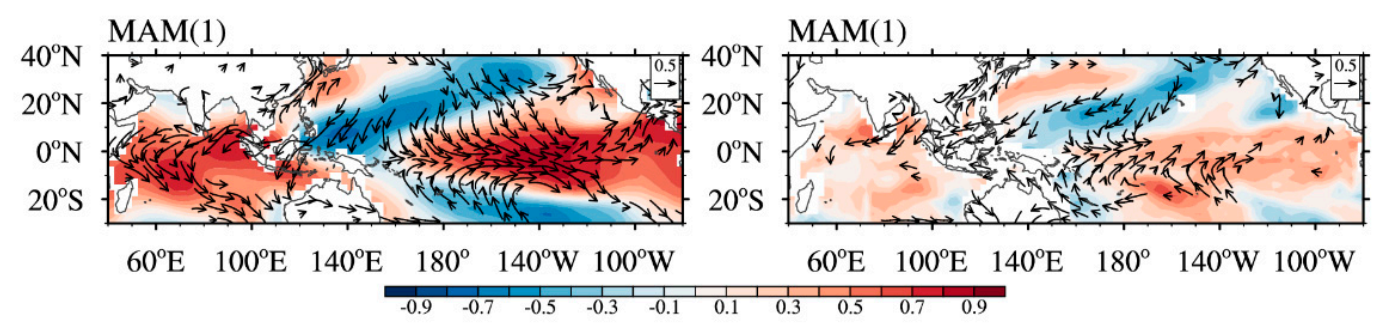

Figure 5. (a) Spatial patterns of the observed correlation fields of seasonal sea surface temperature (SST) anomalies (shading) and $850 \mathrm{hPa}$ wind anomalies (vectors) against the corresponding first principal component from JJA(0) to MAM(1). (b) Same as in (a) except for NESMv3 simulation.

NESMv3 is able to capture the observed rainfall evolution with PCC values of $0.74,0.63,0.77$, and 0.59, respectively, from JJA(0) to MAM(1) (Figure 4a, right panels). In general, NESMv3 overestimates the precipitation over the equatorial eastern Indian Ocean and western Pacific, and the Maritime Continent, and underestimates the precipitation over the western Indian Ocean. NESMv3 reasonably simulates the associated spatial pattern of SST anomalies over the Pacific, but underestimates the amplitude, and the variability center shifts westward (Figure 5b), which may partially contribute to the precipitation bias over the AAM region. A zonal SST dipole with cold water to the east and warm water to the west of the WNP (SIO) anticyclone center maintains (amplifies) the WNP (SIO) anticyclone through local air-sea interaction during a decaying (developing) El Nino. NESMv3 realistically captures the zonal SST dipole associated with the WNP anticyclone in MAM(1), but the dipole and the anticyclone center shift northeastward (Figure 5b). In addition, the model fails to demonstrate the distribution of cold and warm SST around the SIO anticyclone in SON(0) (Figure 5b). These may potentially contribute to the relatively poor performance of NESMv3 in simulating AAM variability during $\mathrm{SON}(0)$ and $\mathrm{MAM}(1)$. 
To examine the relationship between the first AAM mode and ENSO, the lead-lag correlation coefficients between the first principle component (PC) and seasonal (three-month mean) Nino3.4 index are calculated (Figure $4 \mathrm{~b}$ ). The observed first mode shows a maximum positive correlation coefficient with Nino3.4 index in $\operatorname{DJF}(0 / 1)$, indicating that the first SEOF mode concurs with El Nino turnaround. NESMv3 faithfully reproduces the first SEOF mode's relationship with El Nino turnaround, but underestimates the positive correlation correlations from $\operatorname{MAM}(0)$ to $\operatorname{MAM}(1)$. The causes of the weaker lead-lag correlation coefficients in NESMv3 simulation may be attributed to the weaker remote ENSO forcing in the model (Figure 5b), which is possibly due to weak amplitude of ENSO simulated by NESMv3.

Figure 6 presents the observed and simulated spatial patterns of the second SEOF mode and its lead-lag relationship with ENSO. In observation, from JJA(0) to $\mathrm{SON}(0)$, the convective dipole over the equatorial Indian Ocean is enhanced, and rainfall over the western North Pacific shifts to the equator (Figure 6a, left panels). In the ensuing $\operatorname{DJF}(0 / 1)$ and $M A M(1)$, wet anomalies intensify over the equatorial western Pacific, and dry anomalies move southeastward from the northern Indian Ocean and southeast Asia to eastern Indonesia and northern Australia. The observed second mode shows a maximum correlation coefficient leading El Nino mature phase by about 1 year, suggesting that it may provide a precursory signal for ENSO. However, the precipitation anomaly patterns of the second SEOF mode from JJA(0) to MAM(1) are poorly simulated by NESMv3 (Figure 6a, right panels), indicating that the monsoon variability prior to the ENSO onset is difficult to reproduce in NESMv3. Besides, the close relationship between the second SEOF mode and El Nino in DJF(1/2) is not captured by NESMv3 (Figure 6b).

Figure 7 shows the seasonal evolutions of the spatial patterns of SST and $850 \mathrm{hPa}$ wind anomalies which are correlated with the corresponding PC of the second SEOF mode in observation and simulation. For observation (Figure 7a), the WNP cyclonic anomaly shifts equatorward from JJA(0) to SON(0). SST anomalies over the tropical eastern Pacific resemble a decaying La Nina pattern in JJA $(0)$. $\mathrm{SON}(0)$ is a transition phase. The warm SST near the date line is the earliest ancestor of El Nino [6], led by intensified rainfall over the Maritime Continent. In the ensuing $\operatorname{DJF}(0 / 1)$ and $\operatorname{MAM}(1)$, the warming SST anomalies near the date line, the WNP cyclonic anomalies and the associated equatorial westerly anomalies further intensify. The precursor becomes more evident. NESMv3 is not able to simulate the associated circulation and SST anomalies with respect to PC2 (Figure 7b). The robust precursor for El Nino development is not captured by NESMv3, and thus, the model fails to simulate the relationship between the second SEOF mode and El Nino in DJF(1/2). The reason why NESMv3 has difficulty in simulating the second SEOF mode may be the lack of significant SST anomaly forcing or the low predictability of precipitation in the transitional phase of ENSO.

Figure 8 presents the models' performance on simulation of the first two leading SEOF modes and their relationship with Nino3.4 index. Surprisingly, NESMv3 shows the best skill in simulating the first SEOF pattern with a PCC of 0.68 and a NRMSE of 0.75 . The possible reasons why NESMv3 can reproduce SEOF1 so accurately are as follows: (1) Although the model-simulated ENSO remote forcing is weaker than that in observation, the WNP and SIO anticyclones, which are the major circulation systems modulating AAM variability, are well simulated (Figure 5); (2) NESMv3 can realistically reproduce the ENSO phase-locking, providing a solid basis for simulating the ENSO-AAM relationship during different ENSO phases; (3) NESMv3 can capture the climatological spatial pattern of precipitation in each season (Figure not shown), which is the essential condition for reproducing the ENSO teleconnection pattern [32]. For the second mode of SEOF, neither the CMIP5 models nor NESMv3 can reproduce the second SEOF pattern and its relationship with ENSO. 
(a) The Second S-EOF mode of precipitation

OBS ( $10.9 \%)$

NESM-V3 ( 8.6\%)
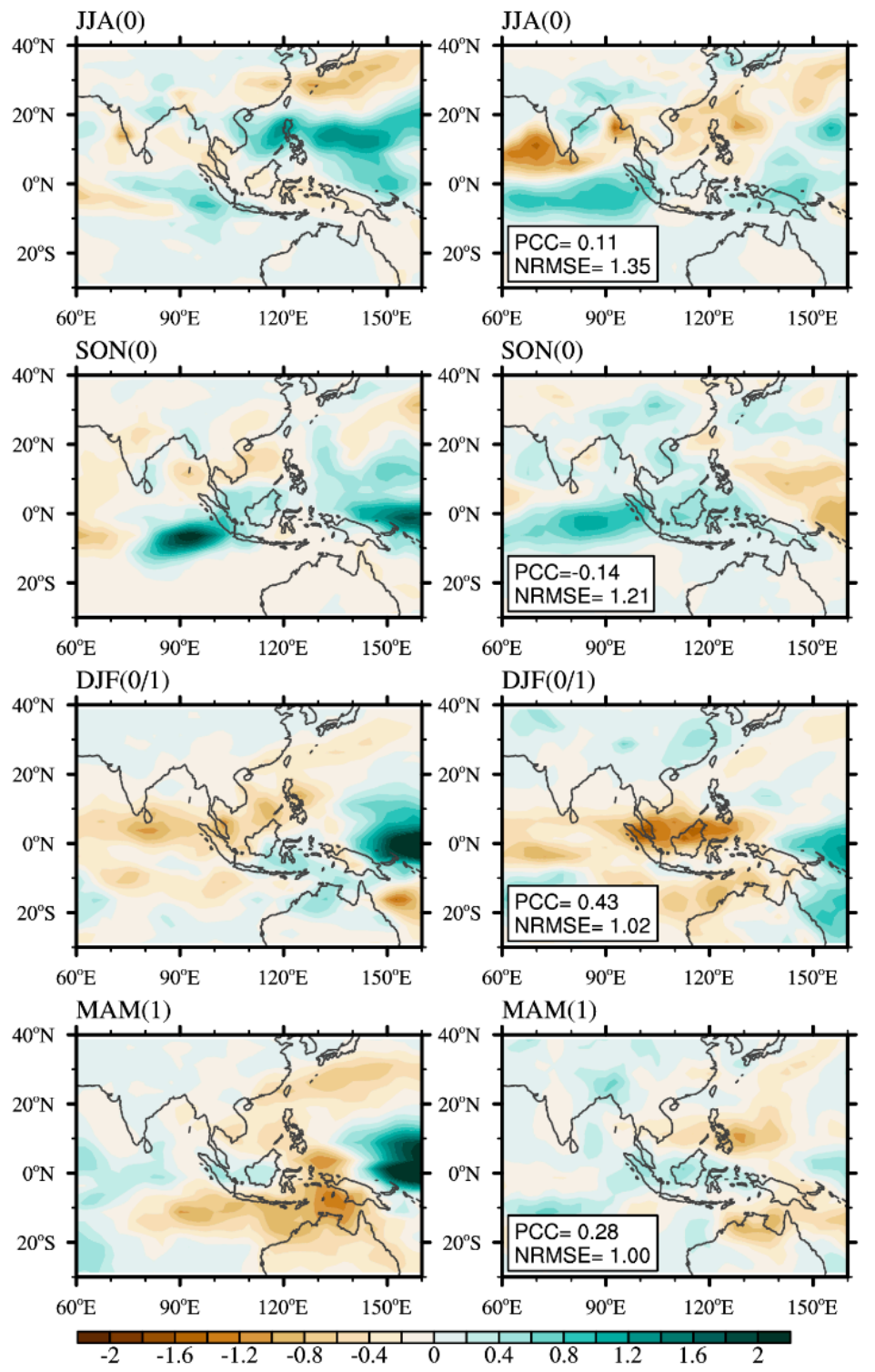

(b) Lead-lag correlation coefficients

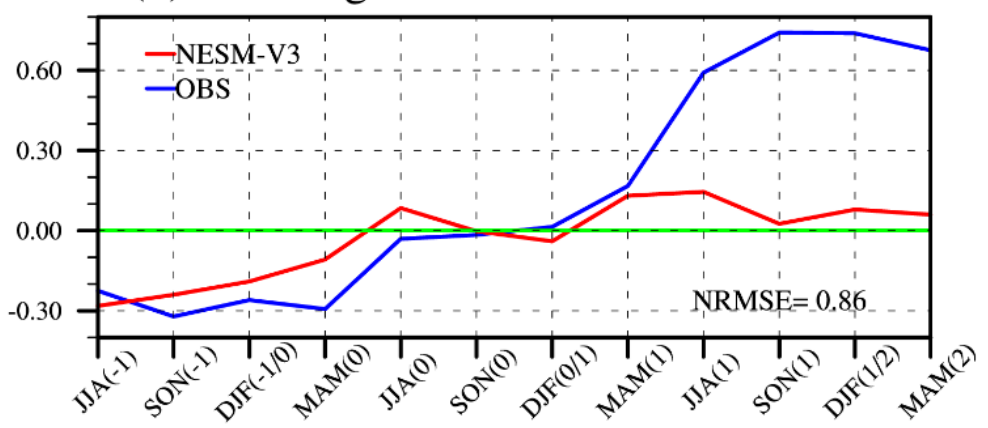

Figure 6. Same as in Figure 4, except for the second SEOF. 
(a) OBS
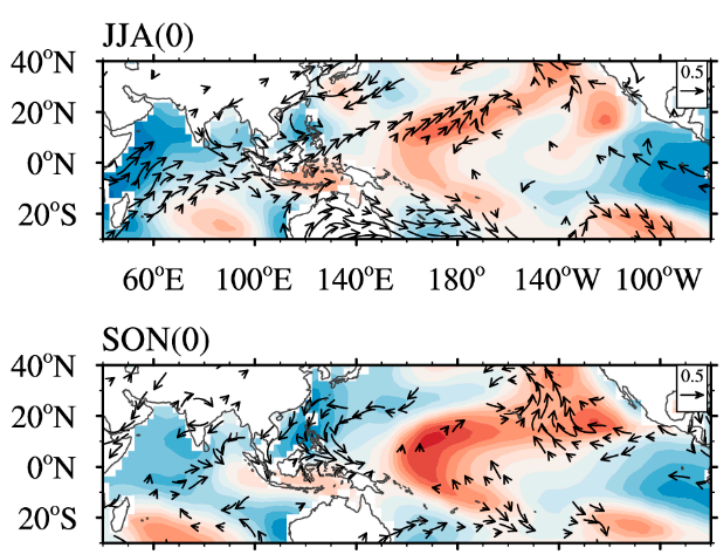

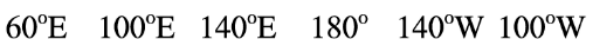

(b) NESM-V3

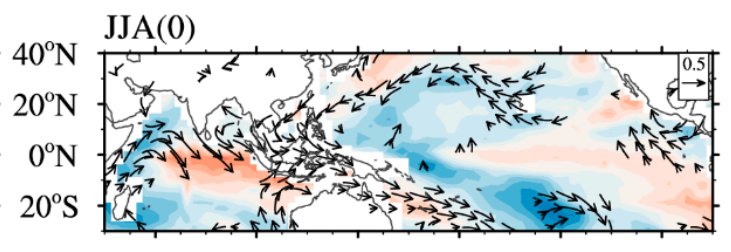

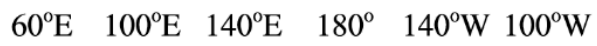

$\mathrm{SON}(0)$

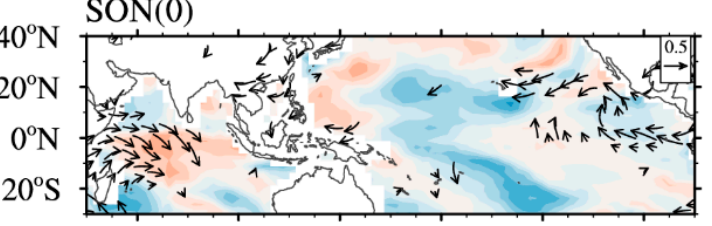

$60^{\circ} \mathrm{E} \quad 100^{\circ} \mathrm{E} \quad 140^{\circ} \mathrm{E} \quad 180^{\circ} \quad 140^{\circ} \mathrm{W} \quad 100^{\circ} \mathrm{W}$

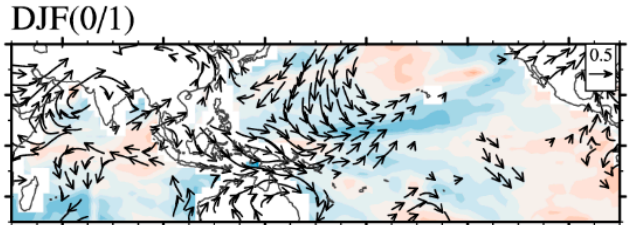

$60^{\circ} \mathrm{E} \quad 100^{\circ} \mathrm{E} \quad 140^{\circ} \mathrm{E} \quad 180^{\circ} \quad 140^{\circ} \mathrm{W} \quad 100^{\circ} \mathrm{W}$

MAM(1)

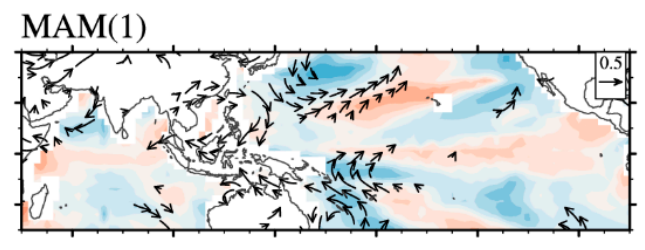

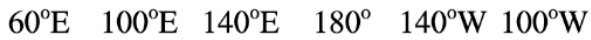

$60^{\circ} \mathrm{E} \quad 100^{\circ} \mathrm{E} \quad 140^{\circ} \mathrm{E} \quad 180^{\circ} \quad 140^{\circ} \mathrm{W} \quad 100^{\circ} \mathrm{W}$

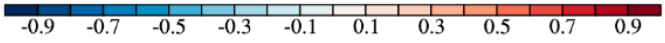

Figure 7. Same as in Figure 5, except for the second SEOF.

(a) SEOF1

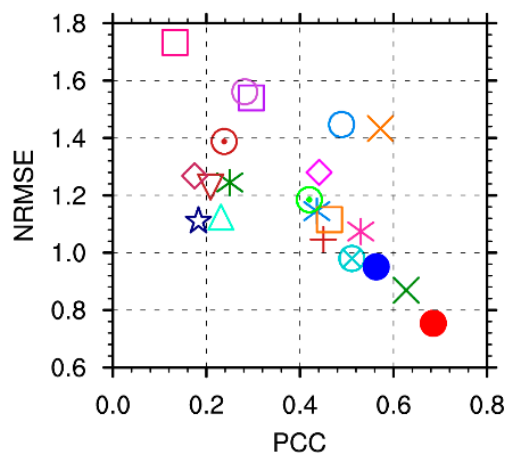

* ACCESS1-0

$\times$ CNRM-CM5

$\triangle$ inmcm4

$\star$ MIROC-ESM-CHEM

MME (b) SEOF2

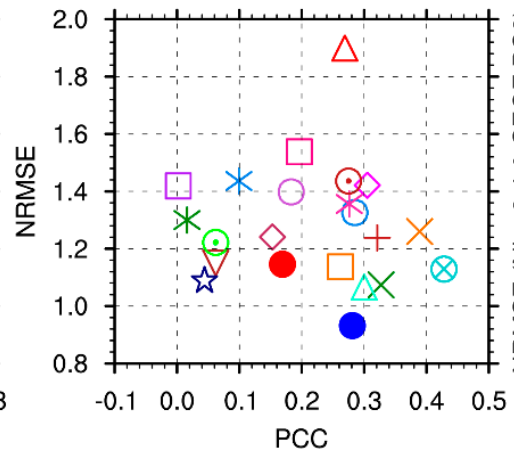

* CanESM2

$\square$ FGOALS-g2

$\diamond$ IPSL-CM5A-MR

$\odot$ MPI-ESM-P (c) Lead-lag Correlation

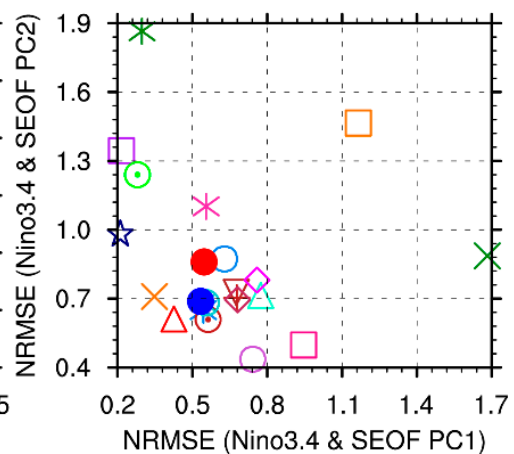

CMCC-CE

GFDL-ESM2G $\triangle$ GFDL-ESM2M

* IPSL-CM5B-LR $\diamond$ MIROC5

○ MRI-CGCM3 $\odot$ NorESM1-M

Figure 8. The models' performance on simulation of (a) the first and (b) the second SEOF mode of precipitation over the AAM region $\left(30^{\circ} \mathrm{S}-40^{\circ} \mathrm{N}, 60^{\circ} \mathrm{E}-160^{\circ} \mathrm{E}\right)$, and (c) the temporal evolutions of lead-lag correlation coefficients between Nino3.4 index and the first/second SEOF principle component. The PCC and NRMSE in $(\mathbf{a}, \mathbf{b})$ are season-averaged value from JJA(0) to MAM(1). 


\section{Conclusions}

In the present study, the performance of NESMv3 in simulating the AAM and its year-to-year relationship with ENSO is evaluated in comparison with that of 20 CMIP5 models and their MME.

Four metrics, including the annual mean precipitation, the annual cycle (seasonal evolution), the monsoon precipitation intensity, and the monsoon domain, are employed to assess the monsoon climatology. (1) NESMv3 reproduces well (PCC $=0.90$, NRMSE $=0.45$ ) the observed features of annual mean precipitation, including the major tropical rain belts in the Indian Ocean/Maritime Continent and the subtropical rain belts over eastern China and Japan; (2) NESMv3 reproduces the solstice mode realistically. However, it overestimates the annual range of precipitation over the south of India, the Indochina Peninsula, the Philippines, the tropical western North Pacific, and the Tibetan Plateau, and underestimates the rainfall range over Australia, the tropical southern Indian Ocean, the Maritime Continent and eastern China, the Korean Peninsula, and Japan. NESMv3 has difficulty in simulating the equinox mode over the AAM region. The major bias in simulation appears over the South China Sea, Indian Ocean, and western Maritime Continent; (3) Generally, the NESMv3-simulated monsoon precipitation intensity over the AAM region agrees reasonably well with the observation. However, it is noteworthy that NESMv3 underestimates the monsoon precipitation intensity over the middle and lower reaches of the Yangtze River, the Korean Peninsula, and southern Japan, whereas it overestimates that over the tropical western Pacific; (4) NESMv3 fails to capture the monsoon domain over parts of eastern China and the East China Sea. Meanwhile, the monsoon domain over the Bay of Bengal, the South China Sea, the western North Pacific, the Maritime Continent and Australia is exaggerated.

SEOF is employed to assess the models' performance in simulating the year-to-year variability of AAM. Besides, its relationship with ENSO is also evaluated. NESMv3 is able to capture the observed first SEOF mode of rainfall seasonal evolution with PCC values of $0.74,0.63,0.77$, and 0.59 , respectively, from JJA(0) to MAM(1). Larger discrepancies are found over the equatorial eastern Indian Ocean and western Pacific. NESMv3 faithfully reproduces the SST anomalies, circulation anomalies (WNP and SIO anticyclonic anomalies) and El Nino turnaround associated with the first SEOF mode. On the contrary, the precipitation anomaly patterns of the second SEOF mode from JJA(0) to MAM(1), and the associated SST and circulation anomalies, are poorly simulated by NESMv3. Meanwhile, the close relationship between the second SEOF mode and El Nino in DJF(1/2) cannot be captured. Most CMIP5 models have difficulty in simulating the second SEOF mode of AAM variability, indicating that the monsoon variability prior to the ENSO onset is difficult to reproduce in current models.

To sum up, NESMv3 shows promising skills in reproducing the AAM climatology, and it also has the capability to simulate the first leading SEOF mode of year-to-year variability involving strong seasonal evolution and its relationship with ENSO. In comparison with 20 CMIP5 models, NESMv3's performance on AAM is among the top three, or above the average level. It is anticipated to be a useful tool for understanding AAM dynamics and predicting its variability. Better simulation of East Asian summer monsoon and western Pacific subtropical high remains a major target for future improvement, in order to provide a reliable tool to understand and predict AAM precipitation.

The model's deficiencies in reproducing the AAM monsoon precipitation may arise from its poor capability to capture the teleconnection of El Nino forcing and monsoon-warm pool interaction [7], poor persistence in seasonal evolution [33], and weak subtropical zonal land-ocean thermal contrast [30]. The means for improving this model's performance on simulating AAM, such as optimized cloud or convective parameterization, still calls for further investigation.

Author Contributions: J.L. analyzed the data and wrote the paper. Y.-M.Y. and B.W. revised the paper.

Funding: This research was funded by the Natural Science Foundation of China (Grant No. 41605035, Grant No. 41420104002), the National Key Research and Development Program of China (Grant No. 2016YFA0600401), the Natural Science Foundation of Jiangsu Province (No. BK20161604), and the Priority Academic Program Development of Jiangsu Higher Education Institutions (PAPD).

Acknowledgments: This is the NUIST-Earth System Modeling Center (ESMC) publication number 233, the SOEST publication number 10434, and the IPRC publication number 1337. 
Conflicts of Interest: The authors declare no conflict of interest.

\section{References}

1. Yasunari, T.; Seki, Y. Role of the Asian monsoon on the interannual variability of the global climate system. J. Meteorol. Soc. Jpn. Ser. II 1992, 70, 177-189. [CrossRef]

2. Krishnamurti, T.N.; Bedi, H.S.; Subramaniam, M. The summer monsoon of 1988. Meteorol. Atmos. Phys. 1990, 42, 19-37. [CrossRef]

3. Krishnamurti, T.; Bedi, H.S.; Subramaniam, M. The summer monsoon of 1987. J. Clim. 1989, 2, 321-340. [CrossRef]

4. Webster, P.J.; Yang, S. Monsoon and enso: Selectively interactive systems. Q. J. R. Meteorol. Soc. 1992, 118, 877-926. [CrossRef]

5. Webster, P.J.; Magaña, V.O.; Palmer, T.N.; Shukla, J.; Tomas, R.A.; Yanai, M.; Yasunari, T. Monsoons: Processes, predictability, and the prospects for prediction. J. Geophys. Res. 1998, 103, 14451-14510. [CrossRef]

6. Wang, B.; Yang, J.; Zhou, T.; Wang, B. Interdecadal changes in the major modes of Asian-Australian monsoon variability: Strengthening relationship with ENSO since the late 1970s. J. Clim. 2008, 21, 1771-1789. [CrossRef]

7. Wang, B.; Wu, R.; Li, T. Atmosphere-warm ocean interaction and its impacts on Asian-Australian monsoon variation. J. Clim. 2003, 16, 1195-1211. [CrossRef]

8. Wang, B.; Kang, I.S.; Lee, J.Y. Ensemble simulations of Asian-Australian monsoon variability by 11 AGCMs. J. Clim. 2004, 17, 803-818. [CrossRef]

9. Wu, R.; Kirtman, B.P. Roles of Indian and pacific ocean air-sea coupling in tropical atmospheric variability. Clim. Dyn. 2005, 25, 155-170. [CrossRef]

10. Sperber, K.; Palmer, T.N. Interannual tropical rainfall variability in general circulation model simulations associated with the atmospheric model intercomparison project. J. Clim. 1996, 9, 2727-2750. [CrossRef]

11. Meehl, G.A.; Arblaster, J.M. The Asian-Australian monsoon and EL Nino Southern Oscillation in the NCAR climate system. J. Clim. 1998, 11, 1356-1385. [CrossRef]

12. Meehl, G.A.; Arblaster, J.M.; Lawrence, D. Monsoon regimes in the CCSM3. J. Clim. 2006, 19, $2482-2495$. [CrossRef]

13. Wang, B.; Lee, J.Y.; Kang, I.S.; Shukla, J.; Kug, J.S.; Kumar, A.; Schemm, J.; Luo, J.J.; Yamagata, T.; Park, C.K. How accurately do coupled climate models predict the leading modes of Asian-Australian monsoon interannual variability? Clim. Dyn. 2008, 30, 605-619. [CrossRef]

14. Taylor, K.E.; Stouffer, R.J.; Meehl, G.A. An overview of CMIP5 and the experiment design. Bull. Am. Meteorol. Soc. 2012, 93, 485-498. [CrossRef]

15. Wang, B.; Yim, S.-Y.; Lee, J.-Y.; Liu, J.; Ha, K.-J. Future change of Asian-Australian monsoon under RCP 4.5 anthropogenic warming scenario. Clim. Dyn. 2014, 42, 83-100. [CrossRef]

16. Adler, R.F.; Huffman, G.J.; Chang, A.; Ferraro, R.; Xie, P.-P.; Janowiak, J.; Rudolf, B.; Schneider, U.; Curtis, S.; Bolvin, D.; et al. The version-2 global precipitation climatology project (GPCP) monthly precipitation analysis (1979-present). J. Hydrometeorol. 2003, 4, 1147-1167. [CrossRef]

17. Xie, P.; Arkin, P.A. Global precipitation: A 17-year monthly analysis based on gauge observations, satellite estimates, and numerical model outputs. Bull. Am. Meteorol. Soc. 1997, 78, 2539-2558. [CrossRef]

18. Lee, J.-Y.; Wang, B. Future change of global monsoon in the CMIP5. Clim. Dyn. 2014, 42, 101-119. [CrossRef]

19. Huang, B.; Thorne, P.W.; Smith, T.M.; Liu, W.; Lawrimore, J.; Banzon, V.F.; Zhang, H.-M.; Peterson, T.C.; Menne, M. Further exploring and quantifying uncertainties for extended reconstructed sea surface temperature (ERSST) version 4 (v4). J. Clim. 2016, 29, 3119-3142. [CrossRef]

20. Cao, J.; Wang, B.; Yang, Y.-M.; Ma, L.; Li, J.; Sun, B.; Bao, Y.; He, J.; Zhou, X. The nuist earth system model (NESM) version 3: Description and preliminary evaluation. Geosci. Model Dev. 2018, 11, $2975-2993$. [CrossRef]

21. Stevens, B.; Giorgetta, M.A.; Esch, M.; Mauritsen, T.; Crueger, T.; Rast, S.; Salzmann, M.; Schmidt, H.; Bader, J.; Block, K.; et al. The atmospheric component of the MPI-M earth system model: ECHAM6. J. Adv. Model. Earth Syst. 2013, 5, 146-172. [CrossRef]

22. Madec, G. Nemo Ocean Engine; Note du Pole de modélisation; Institut Pierre-Simon Laplace (IPSL): Paris, France, 2008; Volume 27. 
23. Hunke, E.C.; Lipscomb, W.H. Cice: The Los Alamos Sea Ice Model Documentation and Software User's Manual Version 4.1. La-cc-06-012; Los Alamos National Laboratory, T-3 Fluid Dynamics Group: Los Alamos, NM, USA, 2010.

24. Craig, A.; Valcke, S.; Coquart, L. Development and performance of a new version of the OASIS coupler, OASIS3-MCT_3.0. Geosci. Model Dev. 2017, 10, 3297-3308. [CrossRef]

25. Zhu, Z.; Li, T. The statistical extended-range (10-30-day) forecast of summer rainfall anomalies over the entire China. Clim. Dyn. 2017, 48, 209-224. [CrossRef]

26. Zhu, Z.; Li, T. Statistical extended-range forecast of winter surface air temperature and extremely cold days over china. Q. J. R. Meteorol. Soc. 2017, 143, 1528-1538. [CrossRef]

27. Wang, B.; Kim, H.J.; Kikuchi, K.; Kitoh, A. Diagnostic metrics for evaluation of annual and diurnal cycles. Clim. Dyn. 2011, 37, 941-955. [CrossRef]

28. Yang, Y.-M.; Wang, B.; Li, J.; Cao, J.; Ma, L. Nuist earth system models v3. Part I: Formulation and historical simulation characteristics based on CMIP6 protocol. Geosci. Model Dev. 2018, in revision.

29. Wang, B.; Ding, Q. Global monsoon: Dominant mode of annual variation in the tropics. Dyn. Atmos. Oceans 2008, 44, 165-183. [CrossRef]

30. Zhu, Z.; He, J.; Qi, L. Seasonal transition of east Asian subtropical monsoon and its possible mechanism. J. Trop. Meteorol. 2012, 18, 305-311.

31. Wang, B.; An, S.I. A method for detecting season-dependent modes of climate variability: S-EOF analysis. Geophys. Res. Lett. 2005, 32, L15710. [CrossRef]

32. Turner, A.G.; Inness, P.M.; Slingo, J.M. The role of the basic state in the ENSO-monsoon relationship and implications for predictability. Q. J. R. Meteorol. Soc. 2006, 131, 781-804. [CrossRef]

33. Hung, C.-W.; Liu, X.; Yanai, M. Symmetry and asymmetry of the Asian and Australian summer monsoons. J. Clim. 2004, 17, 2413-2426. [CrossRef]

(C) 2018 by the authors. Licensee MDPI, Basel, Switzerland. This article is an open access article distributed under the terms and conditions of the Creative Commons Attribution (CC BY) license (http:/ / creativecommons.org/licenses/by/4.0/). 